\title{
Utilization of location-based services for the design of agricultural sales applications
}

\author{
Moch Taufik ${ }^{1}$, Sam Farisa Chaerul Haviana ${ }^{2}$, Dedy Kurniadi ${ }^{3}$ \\ ${ }^{1}$ Universitas Islam Sultan Agung/Jurusan Teknik Informatika \\ Jl. Raya Kaligawe KM., e-mail: mtaufik@unissula.ac.id \\ ${ }^{2}$ Universitas Islam Sultan Agung/Jurusan Teknik Informatika \\ Jl. Raya Kaligawe KM., e-mail: sam@unissula.ac.id \\ ${ }^{3}$ Universitas Islam Sultan Agung/Jurusan Teknik Informatika \\ Jl. Raya Kaligawe KM., e-mail: ddy.kurniadi@unissula.ac.id
}

\section{ARTICLE INFO}

Article history:

Received 14 September 2017

Received in revised form 13 December 2017

Accepted 22 January 2018

Available online 25 January 2018

\section{ABSTRACT}

Onion is one of the main income sectors in Brebes Regency, since most of Brebes area is rice field. Climate and soil type in Brebes is very suitable for onion cultivation plus onion has a high selling value compared to other agricultural products, it makes onion become the main choice of agricultural citizens. The magnitude of the red shadow from Brebes supplies $23 \%$ of national needs. One common problem that arises is how to bridge or facilitate farmers to offer their crops, and make it easier for buyers to locate farmers who sell their crops. One solution is the development of a system that can be an e-commerce web for a special sales promotion media for Gapoktan members (Combined Farmer Group) in Brebes District that will connect sellers and buyers online, and location search media for buyers to more easily find distribution location of the seller by using Location Based Service.

Keywords: Location Based Service, Onion

\section{Pendahuluan}

Bawang merah merupakan salah satu sektor pendapatan utama di Kabupaten Brebes, mengingat sebagian besar area Brebes merupakan persawahan. iklim dan jenis tanah di Brebes sangat cocok untuk pembudidayaan bawang merah ditambah bawang merah memiliki nilai jual yang tinggi di bandingkan hasil pertanian lain, hal tersebut membuat bawang merah menjadi pilihan utama pertanian warga. Besarnya hasil bayang merah dari Brebes ini menyuplai $23 \%$ kebutuhan nasional [1]. Petani bawang di Kabupaten Brebes bergabung dalam paguyuban Gabungan Kelompok Tani yang dikenal dengan nama Gapoktan. Gapoktan membawahi beberapa kelompok tani yang di dalamnya aktif membantu usaha pengembangan, penyuluhan para petani, koperasi dan pertukaran informasi penjualan dan pemasaran antar petani bawang merah. Salah satu keuntungan dalam komunitas ini ialah membantu memasarkan hasil pertanian antar anggota Gapoktan agar petani memiliki posisi tawar yang lebih tinggi, dibandingkan jika dia tidak bergabung dengan Gapoktan. Selama ini, petani secara pribadi tidak memiliki posisi tawar yang tinggi dibandingkan dengan tengkulak yang membeli hasil pertanian [2]. 
Berdasarkan latar belakang di atas maka penulis tertarik untuk membuat suatu rancang bangun aplikasi untuk menjembatani atau mempermudah para petani untuk menawarkan hasil panennya, dan mempermudah para pembeli untuk menemukan lokasi petani yang menjual hasil panen. Dalam pengembangan sistem ini nantinya akan ada web e-commerce untuk media promosi penjualan bawang merah khusus anggota gapoktan di Kabupaten Brebes yang akan menghubungkan penjual dan pembeli secara online, serta media pencarian lokasi untuk pembeli agar lebih mudah mencari sebaran lokasi penjual.

Dari penjelasan mengenai kondisi yang dihadapi oleh petani bawang merah di Brebes, maka rumusan masalah pada penelitian ini adalah sebagai berikut :

1. Bagaimana mengembangkan aplikasi berbasis web untuk interaksi antar anggota dalam gapoktan.

2. Bagaimanakah menyediakan layanan pencarian petani yang memiliki hasil panen bawang merah berbasis lokasi yang dapat dengan mudah diakses oleh pembeli.

\section{Metode Penellitian}

Penelitian ini bertujuan untuk mengembangkan sebuah aplikasi berbasis web dan berbasis lokasi (location based service) yang akan memudahkan pembeli bawang merah partai besar yang langsung bertemu dengan petani penghasil bawang merah. Penelitian rancang bangun aplikasi ini akan mengikuti SDLC (System Development Life Cycle) model Waterfall, dimana model ini akan dimulai dengan fase analisa kebutuhan perangkat lunak, desain perangkat lunak, baik high level design maupun low level design. Kemudian aplikasi perangkat lunak yang akan dibangun, menggunakan pendekatan struktural berbasis web. Fase selanjutnya yang akan dilakukan adalah pengujian aplikasi menggunakan metode black box testing dan white box testing. Sedangkan untuk mendapatkan data pada penelitian ini akan dilakukan penggalian kebutuhan sistem melalui wawancara. Wawancara detail akan dilakukan dengan anggota salah satu gabungan kelompok tani bawang, di Kabupaten Brebes, karena Kabupaten Brebes sebagai penghasil bawang merah terbesar secara nasional, dimana di sana terdapat beberapa kelompok tani bawang merah. Kemudian pengembangan aplikasi dilakukan di Laboratorium Teknik Informatika, Universitas Islam Sultan Agung, Jl Kaligawe Km 4, Semarang. Fase-fase dalam metodologi penelitian ini adalah sebagai berikut:

\section{Fase Analisa Kebutuhan}

Pada fase analisa kebutuhan perangkat lunak, akan dilakukan wawancara dengan anggota gabungan kelompok (Gapoktan) tani bawang di Kabupaten Brebes, untuk menjawab permasalahan tentang penjualan hasil panenan bawang merah di lokasi anggota gapoktan dan mengetahui profil pengguna sistem informasi yang akan dibuat.

\section{Fase Perancangan Sistem}

Fase perancangan sistem dapat dilakukan setelah peneliti mendapatkan hasil dari wawancara yang dilakukan. Proses bisnis jual beli bawang merah, alir data (data flow diagram), diagram hubungan antar entitas (entity relation diagram), struktur basis data dan desain antarmuka web untuk dirumuskan pada fase ini, dan lebih mempertajam rancangan sistem informasi berbasis web dan berbasis lokasi. Desain pengujian sistem akan dilakukan berdasarkan antar muka sistem yang dibuat. Skenario-skenario resiko yang akan terjadi diperhatikan juga untuk membuat rencana pengujian sistem, agar pengguna sistem dapat menggunakan sistem ini dengan baik.

\section{Fase Pengembangan Aplikasi}

Pada fase ini, akan dilakukan pembuatan pengkodean (coding) dan antarmuka pengguna menggunakan PHP, Mysql, berdasarkan rancangan sistem yang telah dibuat pada fase

Utilization of Location-based Services For The Design of Agricultural Sales Applications (Moch 
sebelumnya. Demikian pula dengan penerapan Google API (Application Program Interface) dari Google agar layanan peta google dapat digunakan, karena sistem ini sangat erat kaitannya dengan layanan (service) dari peta yang disediakan oleh Google.

\section{Fase Pengujian Sistem}

Pengujian sistem akan dilakukan sesuai dengan dokumen perencanaan pengujian sistem yang telah dibuat, baik itu berdasarkan black box testing dimana penguji sistem / peneliti mencoba menggunakan sistem tanpa tahu kode program apa yang diuji, dan juga dengan metode white box testing, dimana pengujian akan dilakukan dengan disertai kode sumber program, sehingga penguji mengerti tentang jalannya algoritma sistem yang akan dibangun. Gambar 2 menunjukkan tahapan metodologi penelitian:

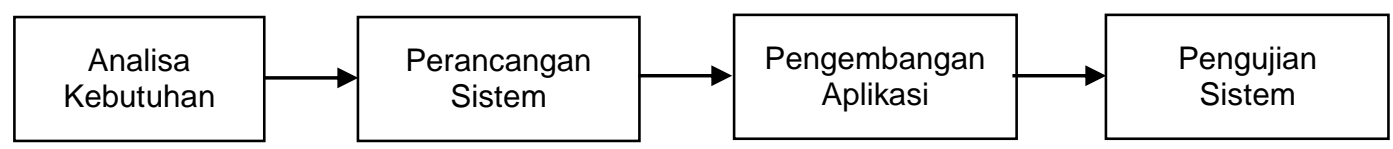

Gambar 1. Tahapan penelitian

\section{Hasil dan Pembahasan}

Aplikasi pada penelitian ini dibangun berdasarkan pola bisnis umum para petani dan pembeli komoditas bawang merah di Kabupaten Brebes. Dimana keduanya memiliki sebaran lokasi yang beragam. Oleh sebab itu layanan berbasis lokasi menjadi komponen terpenting dalam pembangunan aplikasi, yang memberikan dampak positif terhadap penyampaian informasi mengenai lokasi petani penyedia bawang kepada paca calon pembeli. Pemanfaatan peta memberikan gambaran yang lebih luas mengenai sebaran lokasi para penjual komoditas bawang merah dalam hal ini petani atau gapoktan yang berada di daerah Kabupaten Brebes. Gambar 3 menunjukkan prototype aplikasi dengan lokasi salah satu penjual komoditas bawang merah dari gapoktan yang sudah menambahkan data lokasinya melalui aplikasi

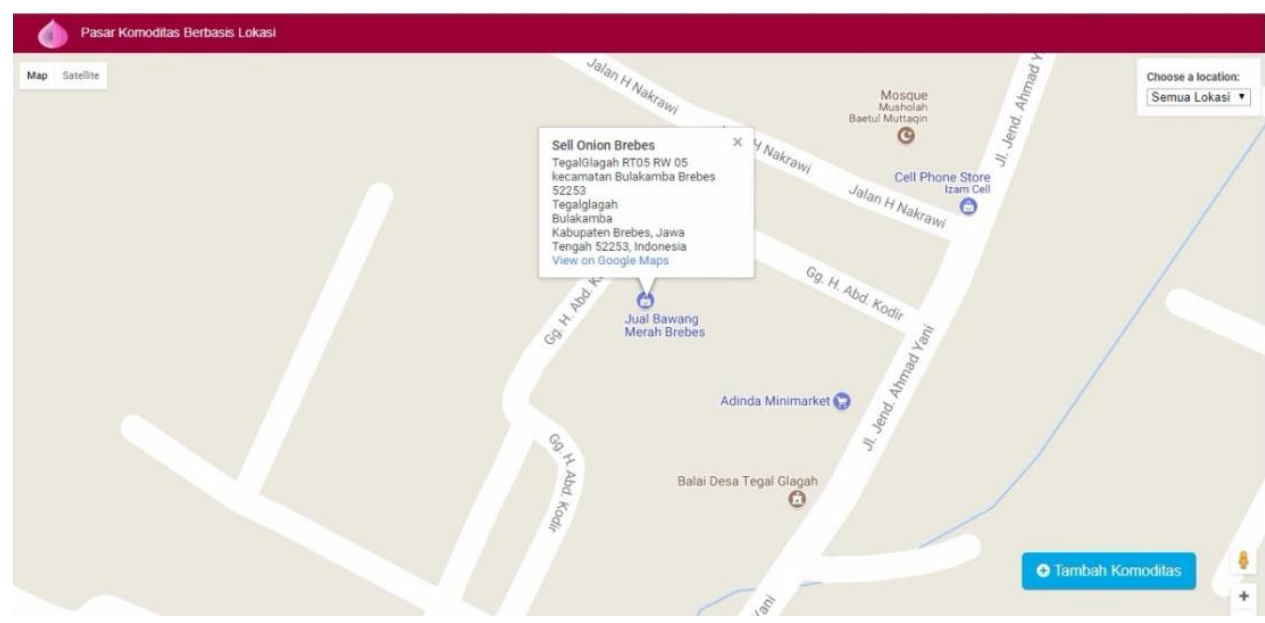

Gambar 2. Lokasi salah satu penjual / penyedia komoditas bawang merah

Lokasi penjual dapat diketahui dengan lebih tepat melalui fitur lokasi pada peta. Ini memberikan gambaran yang lebih akurat mengenai sebaran lokasi para penjual komoditas bawang merah di Kabupaten Brebes. Dengan demikian para pencari komoditas bawang dapat pula mengetahui jarak dan perkiraan waktu tempuh untuk menjangkau lokasi penyedia komoditas

TRANSFORMATIKA Vol. 15, No. 2, January 2018: 128-132 
bawang. Gambar 2 menunjukkan aplikasi dengan perkiraan jarak lokasi penyedia, dalam hal ini petani atau gapoktan dengan calon pembeli atau pencari komoditas bawang merah.

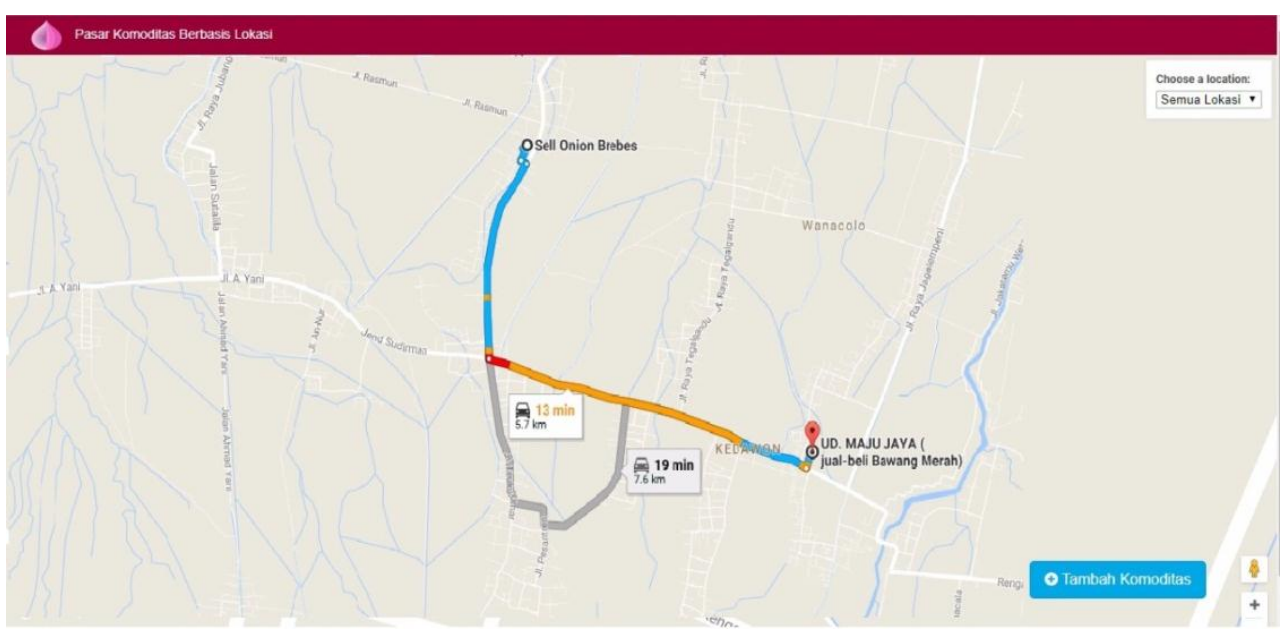

Gambar 3. Perkiraan Jarak dan Waktu Tempuh Lokasi Penyedia Bawang Merah

Hasil rancangan dan pengembangan aplikasi ini juga memberikan kesempatan bagi para petani atau gapoktan untuk secara mandiri membagikan informasi mengenai lokasi dan persediaan bawang merah yang siap jual. Ini memberikan kesempatan pada para petani untuk mendapatkan calon pembeli yang lebih banyak. Dengan demikian ada potensi bagi para petani untuk meningkatkan jumlah pendapatannya dengan hanya menawarkan melalui aplikasi ini. Gambar 6 menunjukkan fungsi dalam aplikasi untuk secara aktif mendaftarkan persediaan bawang merah mereka yang siap jual melalui aplikasi

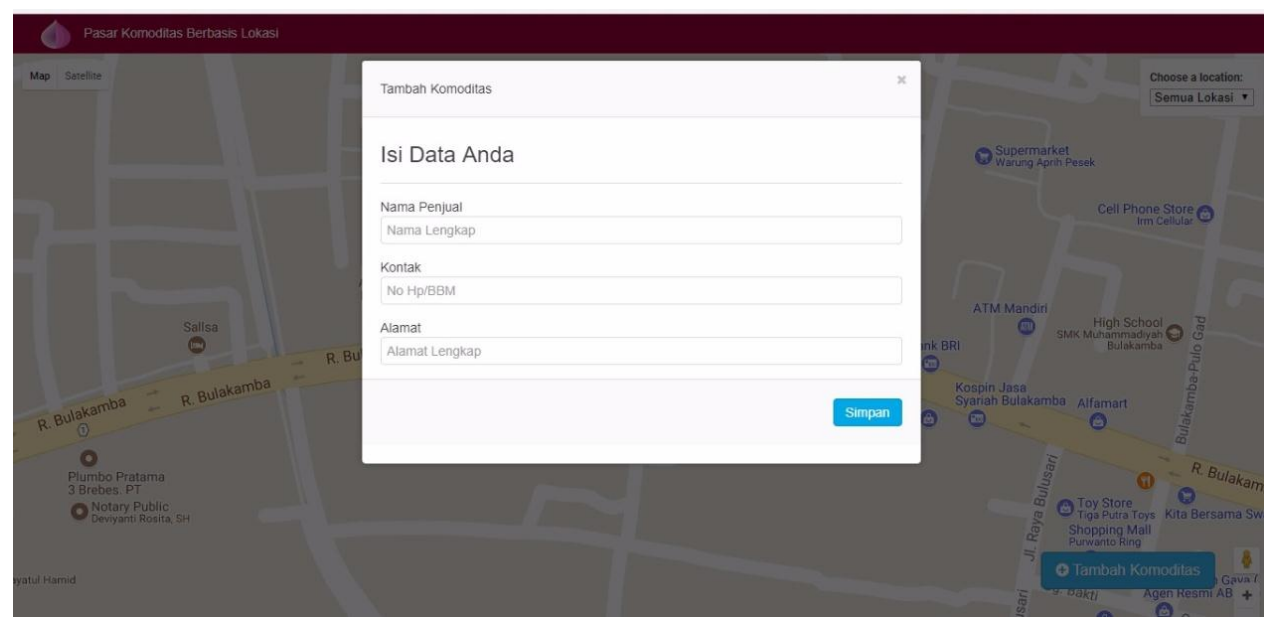

Gambar 4. Form Pendaftaran Penyedia Komoditas

Rancang bangun prototype aplikasi ini cukup untuk memberikan layanan dasar bagi para penjual bawang merah untuk memasarkan produknya melalui internet dengan memanfaatkan layanan berbasis lokasi. Peluang untuk memperkaya fitur pada aplikasi juga masih sangat terbuka bagi penelitian selanjutnya. Yang menjadi tantangan terbesar adalah jumlah partisipasi petani

Utilization of Location-based Services For The Design of Agricultural Sales Applications (Moch 
yang belum maksimal dalam memanfaatkan aplikasi, namun tentu saja masih berpeluang untuk tenjadinya peningkatan jumlahnya.

Hasil penelitian ini juga menunjukkan bahwa partisipasi petani dan gapoktan dipengaruhi oleh tingkat usia para petani. Petani dengan usia lebih lanjut cenderung masih memilih memasarkan melalui model pemasaran konvensional melalui tengkulak. Jumlah partisipasi yang berbeda ditunjukkan oleh para petani yang memiliki usia 40 tahun ke bawah. Dengan pengetahuan dasar dan akses internet memberikan dampak yang lebih positif terhadap pemanfaatan aplikasi pada penelitian ini.

\section{Kesimpulan}

Meskipun layanan berbasis lokasi memberikan fitur yang lebih menarik dan mampu memberikan dampak positif terhadap penyebaran informasi, namun dari hasil penelitian menunjukkan bahwa tingkat efektifitas penggunaan aplikasi sangat bergantung pada komunitas (gapoktan) dan tinggi rendahnya penggunaan internet. Hal ini ditunjukkan dengan hanya sebagian kecil dari gapoktan yang menambahkan komoditi pada aplikasi. Hal ini juga dipengaruhi tingkat umur para petani yang rata-rata sudah memasuki usia tua sehingga semakin sedikit pula memanfaatkan penggunaan teknologi internet meskipun data dari kemenkominfo menunjukkan partisipasi petani yang cukup tinggi namun pada penelitian ini menunjukkan jumlah pengguna internet dari petani yang masih relatif kecil. Tantangan selanjutnya adalah bagaimana agar siste yang memanfaatkan layanan berbasis lokasi ini menjadi layaknya e-marketplace bagi para penyedia komoditas kebutuhan pangan.

\section{Referensi}

[1]. Kebijakan Pemerintah Daerah Kabupaten Brebes Dalam Pemberdayaan Petani Bawang Merah, Apriyanto, Journal of Politic and Government Studies Volume 2, Nomor 2, 2013

[2]. Perspektif Pemasaran Bawang Merah di Kabupaten Brebes, Jawa Tengah, Henny, Valeriana, pse.litbang.pertanian.go.id/ind/pdffiles/MKP_A4.pdf

[3]. Aplikasi Location Based Service SPBU di Wilayah Bandung Tengah berbasis Android http://repository.widyatama.ac.id/xmlui/handle/123456789/3520

[4]. Perancangan Aplikasi Location Based Service Rumah Sakit Yogyakarta Pada Android, Ragil Tri Dianti Putri, dkk, Seminar Nasional Informatika 2013 (semnasIF 2013), 2013

[5]. Pengembangan Aplikasi Layanan Informasi Wisata Budaya Yogyakarta Berbasis Mobile Web dan Location-Based Service, Univeristas Atma Jaya, 2014

[6]. Sistem Aplikasi Location Based Service untuk Pengembangan Kota Cerdas Secara Kolaboratif, Agus Sukerta, Jurnal Teknologi Elektro, Vol.14, No.1, 2015

[7]. The Development of Online Disaster Information System Using Location Based Service (LBS) Technology, Nasaruddin, dkk, International Journal of Informatics and Communication Technology (IJ-ICT), 2014 